www.jmscr.igmpublication.org

Impact Factor (SJIF): 6.379

Index Copernicus Value: 79.54

ISSN (e)-2347-176x ISSN (p) 2455-0450

crossrefDOI: https://dx.doi.org/10.18535/jmscr/v6i11.86

\title{
An observational clinical study to find out most common causes of SIRS at Sher-E-Bangla Medical College
}

\author{
Authors \\ Dr Proshanta Roy ${ }^{1^{*}}$,Dr Joyti Rani Biswas ${ }^{2}$ \\ ${ }^{1}$ Assistant Professor Surgery. Dhaka Community Medical College and Hospital, Dhaka, Bangladesh \\ ${ }^{2}$ Medical Officer, Gynae and Obs. Upazila Health Complex, Agailjhara Barisal \\ *Corresponding Author \\ Dr Proshanta Roy \\ Assistant Professor Surgery. Dhaka Community Medical College and Hospital, Dhaka, Bangladesh
}

\begin{abstract}
Introduction: Systemic inflammatory response syndrome (SIRS) is an uncommon however severe complication in surgical patients whereas SIRS is documented, it's poorly represented within the pediatric population.

Objective: This clinical study mainly focuses on finding out most common abdominal surgical causes.

Method: Causes of SIRS were recorded prospectively each day for all patients. This outcome of study measures based on the type of operation, clinical features, types of disease and complication after surgery.

Results: The most common causes of abdominal surgical are a malignant disease. Almost $30 \%$ patients were suffering on SIRS because of malignant disease. Rather than GI perforation, volvulus and obstruction, burst appendicitis, strangulated hernia was taken a significant place in this study.

Keywords: Systemic inflammatory response syndrome, Malignant disease, GI perforation.
\end{abstract}

\section{Introduction}

Intense general inflammatory response syndrome (SIRS) following non-intestinal surgeries has been documented within the literature predominantly in adults who are otherwise healthy patients. This has been characterized in younger, however to a so much lesser degree. Importantly, vital SIRS following intestine resections or lysis of adhesions, within the absence of infection, intestine perforation or mortification has not been represented within the literature. The etiology of those SIRS events additionally remains poorly understood. Sudden, mysterious instability or shock following what ought to be a routine surgery will cause lasting morbidity or may be death. Integral to treating shock is addressing the underlying supply. Thus, distinguishing risks and responsible factors might enable physicians to higher optimize patients preoperatively, manage patients perioperatively and probably stop this prejudicious outcome from occurring.

Isolated cases of profound operative stress responses or SIRS following viscus surgery or adhesiolysis are anecdotally noted by medical specialty surgeons conducted at Department of Surgery, Sher-E-Bangla Medical faculty Hospital, Barisal from Gregorian calendar month 2006 to calendar month 2007. 


\section{Method}

Study type: This study was clinical and observational studies.

Study time period and location: The study was conducted at the Department of Surgery, Sher-EBangla Medical College Hospital, Barisal from calendar month 2006 to June 2007.

Study sample: In total 50 patients were appear at surgery at patients department Sher-E-Bangla Medical College Hospital, Barisal. Among all of the 15 patients were female and 35 patients are male. Average patients age were $48.82+/-16.75$ years. Mean time period was to developed SIRS between $4.24 \pm 2.53$ days.

\section{Data Analysis}

Collected all the data were preview and edited after collection. After that all the data were input in the computer for statistical analysis. Mainly SPSS-13 (SPSS Inc, Chicago, IL, USA). The results were presented in tables and figures; lite statistical terms included in this study were mean median, standard deviation and percentage.

\section{Results and Observation}

Table-1: Age distribution table

\begin{tabular}{|l|c|c|}
\hline Age in years & Frequency & Percentage \\
\hline $15-24$ & 5 & 10.0 \\
\hline $25-34$ & 6 & 12.0 \\
\hline $35-44$ & 8 & 16.0 \\
\hline $45-54$ & 11 & 22.0 \\
\hline $55-64$ & 12 & 24.0 \\
\hline $65+$ & 8 & 16.0 \\
\hline Total & 50 & 100.0 \\
\hline
\end{tabular}

Mean SD (Range) $48.82 \pm 16.75$

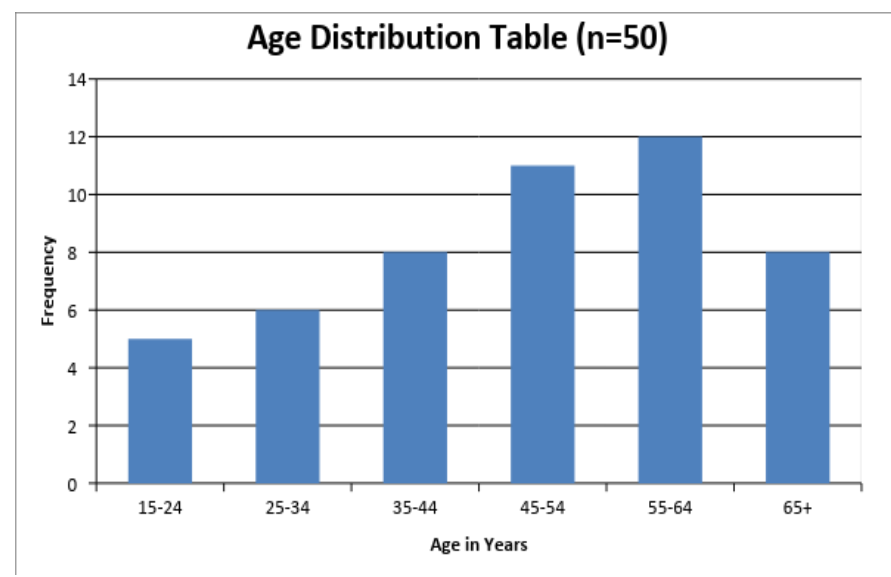

Above table and graph shows age distribution of patients. Majority $24 \%$ of patients suffer in SIRS and their age in between 55-64 years. Other age group followed by $22 \%$ within $45-54$ years age groups, behind it $16 \%$ patients of 35-44 years and above 65 years. Rest of $12 \%$ patients $25-34$ years and $10 \%$ patients were in $15-24$ year age group.

Table-2: Sex distribution of patients

\begin{tabular}{|l|c|c|}
\hline Sex & Frequency & Percentage \\
\hline Male & 35 & 70 \\
\hline Female & 15 & 30 \\
\hline Total & 50 & 100 \\
\hline
\end{tabular}

\section{Sex Distribution Chart}

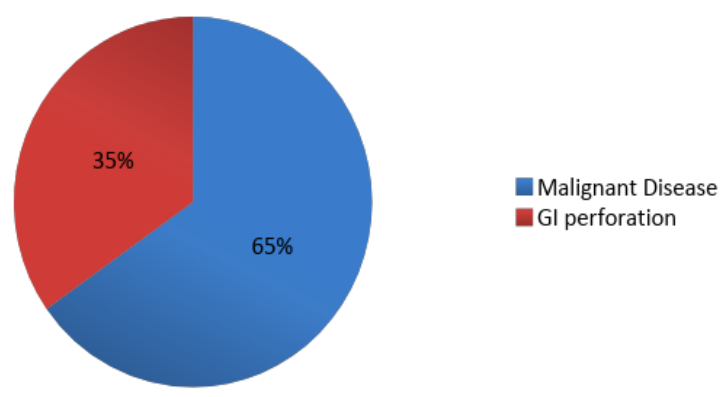

Figure: Sex Distribution Chart.

From table-2 and above pie chart it easily measurable the sex distribution of patients. Around 50 patients who had SIRS in postoperative period. Among them 70\% were male and $30 \%$ patients were female. Ratio of male and female was 2.33:1.

Table-3: Types of Disease

\begin{tabular}{|l|c|c|}
\hline Types of Disease & Frequency & Percentage \\
\hline Malignant Disease & 15 & 30 \\
\hline GI perforation & 8 & 16 \\
\hline Volvulus and obstruction & 7 & 14 \\
\hline Burst appendecits & 4 & 8 \\
\hline Strangulated hernia & 6 & 12 \\
\hline Cholilithiasis & 4 & 8 \\
\hline RTA & 4 & 8 \\
\hline Others & 2 & 4 \\
\hline Total & 50 & 100 \\
\hline
\end{tabular}

Above table represents different types of diseases. Among all patients $16.0 \%$ had GI perforation, $14 \%$ had volvulus, $8.0 \%$ had burst appendicitis, $12.0 \%$ had strangulated hernia, $8.0 \%$ had cholilithiasis, $30.0 \%$ had malignant disease, $8.0 \%$ had RTA and $4.0 \%$ had some oilier problem. 


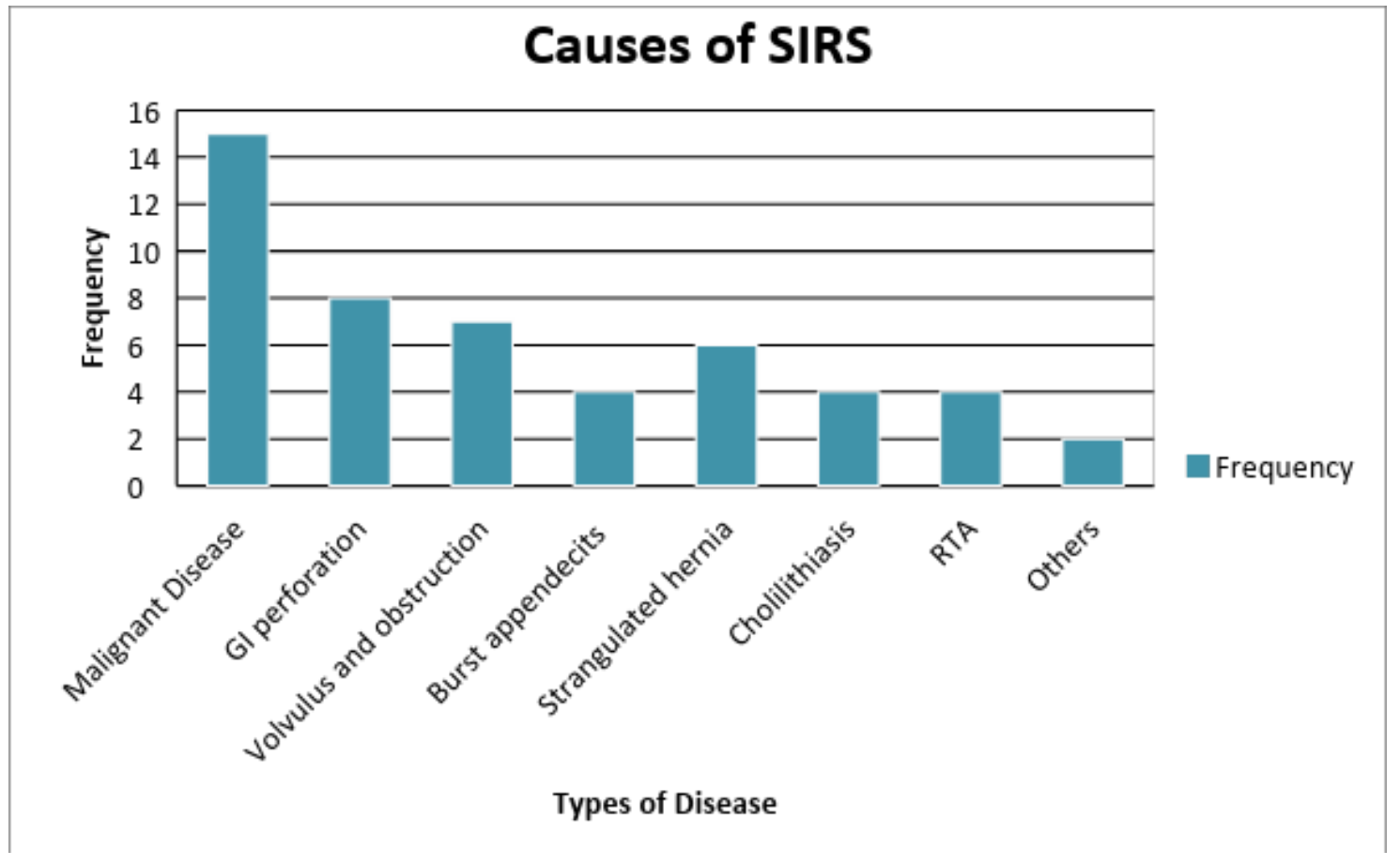

Above figure shows the reason of SIRS. This graph shows that 15 patients suffer in SIRS because of malignant disease, 8 patients for GI perforation followed by 7 patients for volvulus and obstruction, 4 patients from burst appendicitis. Rest of the patients were suffering SIRS because of Strangulated hernia (6 patients), cholelithiasis (4 patients), RTA (4 patients) and other (2 patients).

Table-4: Types of operation

\begin{tabular}{|l|c|c|}
\hline Types of operation & Frequency & Percentage \\
\hline Emergency & 30 & 60 \\
\hline Schedule & 20 & 40 \\
\hline Total & 50 & 100 \\
\hline
\end{tabular}

Above table shows that, operation types during the study period. Maximum 30 patients (60\%) appeared in an emergency operation and 20 patients $(40 \%)$ appear in schedule operation.

Table-5: Clinical findings after developing SIRS

\begin{tabular}{|l|c|c|}
\hline Clinical Sign & Frequency & Percentage \\
\hline Temperature $>36^{\circ} \mathrm{C}$ & 40 & 80 \\
\hline Pulse rate $>$ 90/min & 42 & 82 \\
\hline Respiration rate $>90 / \mathrm{min}$ & 45 & 70 \\
\hline $\begin{array}{l}\text { Total WBC count > } \\
\text { 1200/cu. Mm }\end{array}$ & 38 & 76 \\
\hline Edema & 30 & 60 \\
\hline Wound infection & 20 & 40 \\
\hline Fecal fistula & 10 & 20 \\
\hline Hypolension & 48 & 96 \\
\hline
\end{tabular}

This table shows clinical features after developing SIRS. Most of the patients had fever $(80.0 \%)$, increased pulse $(82.0 \%)$, tachypnoea $(70.0 \%)$ and edema (60.0\%). Only $40.0 \%$ had wound infection and $20.0 \%$ had the fecal fistula.

\section{Discussion}

Development of SIRS in post operative period is multi factorial. People who are economically developed and conscious about their health have less chance to develop diseases followed by less post operative complication SIRS. On the other hand people who are economically poor and illiterate are more likely to develop diseases followed by post operative complication SIRS. Communication additionally plays a task as some operative cases cannot reach the hospital incorrect time thanks to lack of vehicle and below developed roads and the main road. Population density decreases nutritional standing and immunity thus will increase the probabilities of development SIRS. Patients load additionally hamper the quality of service. In the present study, $70 \%$ male and $30 \%$ female had developed SIRS. Similar to our study $72.0 \%$ were male and $28.0 \%$ were female in NeSmilah el $\mathrm{al}^{39}$ series. In Mokart et al series male and female ratio was 1:1 and was not comparable with the present study. Male was 
more in our study as they work outside their residence, hormonal influence, some disease like PUD, inguinal hernia, malignancy, volvulus more in male ${ }^{4}$. Age conjointly influences the event of SIRS. In early ages, typically diseases are less, \{may be could conjointly basis also because of sensible nutritionary standing and also for extremely acquired immunity system. In middle and previous ages, folks develop additional malady so additional SIRS. Pure gold patients of 55-64 years, 20 second of 45-54 years, Sixteen Personality Factor Questionnaire in each 35-44 and 64+ age teams had developed SIRS. Mean age of the study cluster was $48.82(+6.75)$. All patients were among fifteen to eighty years.

In NcSmith $c t$ at ${ }^{39}$ series mean (SD) age of all patients was with range age 18 to 44 years. Maximum patients belonged to 18 to 26 years age group followed by $28.0 \%$ to 36 to 44 years age group.

All operative cases don't seem to be equally liable for SIRS. Some cases like GI perforation, volvulus, and obstruction, burst appendicitis, strangulated hernia, square measure saw for the event of SIRS. Here microorganism contamination and tissue death happen at the same time. Major trauma decreases self-protection by immunity and facilitate Transmigration of various small organism. On the opposite hands, malignant illness decreases the body immunity and organic process standing of the patients and older age bracket conjointly an element to develop SIRS. In the present series of SIRS $16 \%$ had a perforation. $14 \%$ volvulus, $8 \%$ burst appendicitis, $12 \%$ strangulated hernia, $8 \%$ cholihthiasis, $30 \%$ malignant disease, $8 \%$ RTA and $4 \%$ other cases. Patients with acute cholecystits, acute cholagitis, perforated ulceration, trauma peptic ulcer, obstruction, little volvulus perforation conic perforation were the foremost frequent in Nishidha et al series.

Types of operation also influence SIRS. 60\% emergency cases and $40 \%$ schedule cases develop SIRS. Numbers of emergency cases are more than schedule cases and schedule cases and in schedule cases, although more complicated operation is done, pre-operative preparation is good and patients selection also play the role for a better outcome.

Most of the patients develop raised temperature (80\%), pulse rate $(82 \%)$, increased respiration rate (70\%), WBC count (76\%), edema (60\%), wound infection (40\%), fecal fistula (20\%) and hypotension (96\%). Many patients are drowsy or unconscious.

\section{Conclusion}

Systemic inflammatory response syndrome, sepsis, severe sepsis, and MODS are common in surgical practice. It has high mortality and morbidity rate. Its pathological process remains clearly unknown. Early recognized SIRS cases are simple to manage. SIRS in a post-operative amount of abdominal surgery might straightforward to manage if early detection is feasible. Operative case choice is additionally played a very important role. Smart teamwork with adequate trendy equipment and ICU facility will scale back SIRS relate mortality and morbidity. Public awareness regarding health, varied national programs regarding health and advertising in physical science media will scale back health connected complication.

\section{Reference}

1. Mokart D. Merlin M, Sannini A, Brun JP, Dclpcro JR, Houvcnacghcl G, Procalcitonin, interleukin 6 and systemic inflammatory response syndrome (SIRS): early markers of postoperative sepsis after major surgery. British Journal of Anaesthesia 2005;94 (6): 767-73

2. NeSmith LG, Weinnch SP, Andrews JO, Medeiros RS, llawkins ML, Wcinrich M. Systemic Inflammatory Response Syndrome Score and Race As Predictors of Length ol' Stay in the Intensive Care Unit. Am J Crit Care. 2009:18: 339-346

3. Bone RC, Balk RA, Cerra FB, Dellinger RP, Fein AM, Knaus WA. et al. 
Definitions for sepsis and organ failure and uidelines fur the use of innovative therapies in sepsis. The ACCP/SCCM Consensus Conference Committee. American College of Chest Physicians/ Society of CriticalCare Medicine. Chest. 1992; 101:1644-1655

4. American College of Chest Physicians/ Society of Critical Care Medicine Consensus Conference, Definitions for sepsis and organ failure, and guidelines for the use of innovative therapies in sepsis. Crit Care Med.1992;20864- 874. 